Peer-Reviewed Article

ISSN: 2162-3104 Print/ ISSN: 2166-3750 Online

Volume 7, Issue 4 (2017), pp. 963-989

(C) Journal of International Students

http://jistudents.org/

\title{
Supporting Chinese Undergraduate Students in Transition at U.S. Colleges and Universities
}

\author{
Kerrie A. Montgomery \\ Florida International University, USA
}

\begin{abstract}
The Chinese undergraduate student population currently represents $12.8 \%$ of all international students enrolled in the United States (Institute for International Education, 2015a). In an effort to understand the experiences of this population in their first year of college in the United States, a phenomenological study was conducted using a conceptual framework comprising Schlossberg's Transition Model (Schlossberg, Waters, \& Goodman, 1995) and the Culturally Engaging Campus Environments (CECE) Model (Museus, 2014). Three transition types were identified academic, social/personal, and linguistic - and participants' preparation, sources of institutional support, and coping strategies for moving through these transitions were examined. Recommendations for practice include: multi-faceted, mandatory orientation programs; ongoing workshops and resources beyond orientation; and improvements to housing and residential life opportunities and experiences.
\end{abstract}

Keywords: CECE model; Chinese undergraduate students; International students; Transition model

International students currently account for $4.8 \%$ of students enrolled at all levels in institutions of higher education in the United States (U.S.) (Institute for International Education [IIE], 2015a). With nearly 5 million international 
students estimated to be studying outside of their home countries worldwide, the United States, hosting approximately $17 \%$ of these students, is considered the top destination for those seeking degrees outside their home countries at both the graduate and undergraduate levels (ICEF Monitor, 2014). In 2013, for the first time in over a decade, the number of international students at the undergraduate level studying in the United States exceeded those at the graduate level (IIE, 2013). Additionally, the highest number of international students enrolled in the United States, $31.2 \%$, were from China (IIE, 2015a).

The Institute for International Education (IIE) (2015a) reports that in 2014/2015, international students contributed over $\$ 30.5$ billion dollars to the U.S. economy in the form of tuition, educational materials, housing, and living expenses. They also add to compositional diversity on campuses and provide diverse perspectives both inside and outside of the classroom (Andrade, 2006; Choudaha, Chang, \& Kono, 2013; Glass, Buus, \& Braskamp, 2013; Lee, 2008, 2010; Smith \& Khawaja, 2011). As a result of increased efforts to internationalize U.S. institutions, universities are actively recruiting international students to provide cultural diversity, enhance academics, and raise the reputation of the institution (Bodycott, 2009; Glass, Buus, \& Braskamp, 2013). Considering the significant financial impact international students have on U.S. institutions and their local communities, and given the value these students bring to campus through their cultural contributions, some scholars feel it is the obligation of U.S. institutions to provide an appropriate level of support to aid them in succeeding (Anderson, Carmichael, Harper, \& Huang, 2009). Student affairs departments and staff play a critical role in aiding international students' transitions to, and success at, U.S. institutions of higher education.

\section{Statement of the Problem}

Since 2009/10, Chinese students have continued to represent the largest number of international students enrolled in U.S. institutions of higher education each year (IIE, 2015b). U.S. institutions are attractive to this population of students because of their strong academic reputations as well as the increased chances for employability upon completion of the degree (Pang \& Appleton, 2004). Since international students are a heterogeneous population, it was appropriate to focus this research on one segment of the population to avoid generalizing the needs of such a diverse population of students. As the population represents $12.8 \%$ of all international students enrolled in the United States and is growing at a faster 
rate than the Chinese graduate population (IIE, 2015b), Chinese undergraduate students were selected for this study.

In undertaking this research, a gap in the literature regarding the persistence rates of international undergraduate students in the United States was identified. Furthermore, in spite of the continued growth of the Chinese undergraduate population, little or no research could be found with regard to understanding the experiences of this student group on campuses in the U.S., and what they have, want, and need in order to succeed in their transition and, ultimately, choose to persist at their institutions. As such, the following research questions were used to guide the study: How do Chinese undergraduate students experience the first year of college at an institution in the United States?

(1) How do they describe their motivations for pursuing a degree in the U.S.?

(2) In what ways do they feel they were prepared to navigate the new environment?

(3) How do they describe the support they had from the institution?

(4) What strategies were most helpful in their transition process?

Although the literature suggests that international students experience many of the same challenges as their domestic minority peers (Hanassab, 2006; Kim \& Kim, 2010; Lee \& Rice, 2007; Reid \& Radhakrishnan, 2003; Watson, et al., 2002), the author's personal observations at various U.S. institutions, and a lack of available literature on the subject, suggest that the same kind of support is not routinely provided for international students as a means of aiding in their transition to college or supporting persistence. The purpose of the study, therefore, was to identify solutions for providing appropriate and relevant support programs and services for this population based upon their first-year experiences. This research was intended to be a first step in beginning to develop such interventions that may ultimately be useful to all international students on U.S. campuses.

\section{LITERATURE REVIEW}

The United States has long been the top host country for international students, and the continued growth of enrollment numbers is due to a variety of "push-pull factors" (Mazzarol \& Souter, 2002), those that push the 
student from their home country and/or pull them toward the host country. Among these factors are: reputation of U.S. higher education overall; reputations of specific institutions; lack of access to higher education in the home country; potential for enhanced employment opportunities at home or in the host country; efforts of U.S. institutions to recruit qualified international students to their campuses; and immigration/visa policies (Altbach, 2004; Bodycott, 2009; Douglass \& Edelstein, 2009; Goodman, 2009; Goodman \& Gutierrez, 2011; IIE, 2013; Lee, 2008; Mazzarol \& Souter, 2002; McMurtrie, 2008).

Tan and Weidman (2013) assert that the trend of increasing numbers of Chinese students in the United States, at both the graduate and undergraduate levels, is likely to continue indefinitely. They attribute this, in part, to "a demand for more advanced academic credentials" (p. 118), which is the result of a highly competitive job market in China. These authors further suggest that economic conditions in both China and the United States make it more attractive for Chinese students to study in the United States, and makes U.S. institutions more interested than ever in recruiting these students who are able to pay their own expenses (Tan \& Weidman, 2013).

As research on international student experiences in the U.S., particularly at the undergraduate level, was difficult to identify, the findings of research conducted on international student experiences in Englishspeaking host countries such as Australia, New Zealand, the United Kingdom, and Canada, was also consulted. The extant literature shows that these students experience many of the same issues encountered by U.S. domestic minority students (Hanassab, 2006; Lee \& Rice, 2007; Kim \& Kim, 2010; Reid \& Radhakrishnan, 2003; Watson et al., 2002). Issues related to the difficulty of domestic minority students in adjusting to the campus environment, feelings of being discriminated against, lack of support, and an expectation by non-minority students and faculty that they are able to serve as informants on behalf of all other minority students are not uncommon (Watson et al., 2002). Similarly, international students in English-speaking countries outside the United States have reported that they feel a lack of institutional support, have difficulty adapting to the new higher education system, and, especially those from non-Western countries, are the targets of bias and stereotyping primarily because of their difficulties with the English language (Lee, 2010). In addition, issues of financial difficulty, perceived discrimination, and adjusting to new pedagogical styles, were also reported in research conducted at Australian institutions (Russell, Rosenthal, \& Thomson, 2010). 


\section{CONCEPTUAL FRAMEWORK}

A conceptual framework comprising Schlossberg's (1995) Transition Model and Museus' (2014) Culturally Engaging Campus Environment (CECE) Model, and incorporating elements of Chinese culture, was employed. The "4 S System" of Schlossberg's Transition Model - Situation, Self, Support, and Strategies - refers to the resources available to an individual in their transition process (Schlossberg, Waters, \& Goodman, 1995). These four elements served as the backbone of the conceptual framework by providing a foundation for understanding the common elements of individuals' transition experiences while respecting their unique personal circumstances.

\section{Schlossberg's Transition Model}

The element of "Situation" encompasses such factors as: things that prompt a transition, the role the individual plays in the transition (i.e., their choice in the situation), and their level of control in the situation (Schlossberg, Waters, \& Goodman, 1995). The element of "Self" refers to those personal resources an individual brings to a transition, including such things as age, gender, socioeconomic status, ethnicity, outlook, and values, each of which may position an individual to transition more or less successfully depending on their circumstance (Schlossberg et al., 1995). The element of "Support" includes those external resources available to an individual in transition, namely, relationships with family members and friends, as well as institutions and communities to which they belong (Schlossberg et al., 1995). Finally, "Strategies" comprises the actual coping mechanisms an individual may use, such as trying to control the situation, or trying to control the stress caused by the situation through avoidance or other tactics (Schlossberg et al., 1995).

\section{Culturally Engaging Campus Environments (CECE) Model}

As was demonstrated in a review of the literature, research has shown that many non-native English-speaking international students in English-speaking environments have reported experiences similar to those of domestic minority students (Hanassab, 2006; Lee \& Rice, 2007; Kim \& Kim, 2010; Reid \& Radhakrishnan, 2003; Watson, et al., 2002). As a result, Schlossberg's Transition Model (1995) was supplemented with the nine indicators of the Culturally Engaging Campus Environment Model (Museus, 2014) in order to examine the support structures in place at institutions in the United States to aid in the transition experiences of Chinese 
undergraduates. Museus (2014) developed the CECE Model to identify ways in which the responsibility for student success, regardless of race or ethnicity, can be more intentionally assumed by the institutions admitting them. The specific aspect of the CECE Model used in this study highlights the environmental and individual influences that affect student success, and "suggests that the degree to which culturally engaging campus environments exist at a particular postsecondary institution is positively associated with more positive individual factors and ultimately greater college student success" (Museus, 2014, p. 207). The nine indicators of a Culturally Engaging Campus Environment proposed by Museus, the presence or absence of which can significantly impact racially diverse students' success, are: Cultural Familiarity; Culturally Relevant Knowledge; Cultural Community Service; Opportunities for Meaningful Cross-Cultural Engagement; Collectivist Cultural Orientations; Culturally Validating Environments; Humanized Educational Environments; Proactive Philosophies; and Availability of Holistic Support.

\section{Chinese Values}

In addition to these models, norms and values inherent in Chinese culture, specifically related to relationships and education, were considered as a component of the element "Self" in the Schlossberg Transition Model (Schlossberg, Waters, \& Goodman, 1995). These two areas are especially relevant for the experience of Chinese students since the literature suggests that the motivation to attend U.S. institutions is largely rooted in familial relationships and expectations and an emphasis on education is an important part of Chinese culture. According to a study comparing Americans and Chinese with regard to academics, for the Chinese, the primary motivation for success came from family and clan responsibility, and children were raised from a very early age "to pursue individual and group achievement in the name of group success" (Yu, 1996, p. 234). Furthermore, Chinese culture encourages children to "overcome their individuality" (Hofstede \& Bond, 1988, p. 8), at least in terms of their actions, in order to maintain harmony and the honor of the family. Additionally, the notion of "maintaining face" is extremely important in Chinese culture. In this concept, one's "dignity, self-respect, and prestige" (Hofstede \& Bond, 1988, p. 8) must remain untarnished in order for harmony (a Confucian value) to exist. Maintaining face on an individual level is critical because it actually affects the "face" of the family and larger community with which one is associated. This value manifests itself in the classroom through the potential 
loss of face for poor performance or misconduct on the part of either the student or the teacher (Chan, 1999). Finally, students in China have been trained to "respect wisdom, knowledge and expertise of parents, teachers and trainers. They have been socialized to respect highly those who provide the knowledge and to avoid challenging those in authority" (Chan, 1999, p. 298). As a result, the Western style of education is often problematic for Chinese students who are not accustomed to the more interactive classroom environments (Chan, 1999).

In order to gain an understanding of the experiences of Chinese undergraduate students during their first year in the U.S., Schlossberg's Transition Model (1995) was selected as a basis for exploring both the internal and external resources that might have aided in the transitions to their new environments. Furthermore, the model's design lent itself to supplementation with other models that could address specific resources in a more directed manner. Because the study focused on students from a minority population at their campuses, and in light of the literature revealing a similarity in experiences between international and domestic minority students, the Culturally Engaging Campus Environments Model (Museus, 2014) was incorporated in the realm of "Support." Additionally, because the population being studied represented a specific culture with unique values, I made the decision to highlight elements of those values within the area of "Self." Finally, since a transition experience also includes the factors that initiated it, in the realm of "Situation" according to Schlossberg et al. (1995), the selection of this framework informed the decision to include motivations and expectations prior to participants' arrival in the U.S. as part of the study of their first-year experience.

\section{RESEARCH METHOD}

A hermeneutical phenomenological approach was used for this study. Phenomenology is intended to examine the lived experiences of several individuals who have experienced the same phenomenon and then identify what they have in common (Creswell, 2007). Hermeneutical phenomenology, according to Kafle (2011), focuses on "illuminating details and seemingly trivial aspects within experience that may be taken for granted in our lives" (p. 191). Furthermore, it encourages the researcher to acknowledge and incorporate their personal biases throughout the analytical process since their personal experiences may relate to what is being researched (Laverty, 2003). Because transition experiences comprise a 
number of factors involving the individuals' situation, self, external sources of support, and coping strategies, an awareness of the details that combined to create their broader experience is necessary in order to interpret the way those factors interacted with one another. As a result, this methodology is complementary to the conceptual framework in that it has, at its core, an interest in the lived experiences of the study participants (Creswell, 2007) and the interpretation of how those experiences shaped their transition.

\section{Participants}

Upon receiving IRB approval from the study site, recruitment of participants was done at a large, public, multi-campus institution in the southeastern United States, using criterion-based sampling. Although this research focused on the first-year transition experiences of the population being studied, that does not imply that the first year of college for participants was the traditional "freshman" year. In fact, some participants had transferred from institutions outside the U.S. to begin their junior year in the United States. Since hermeneutical phenomenology is a reflective approach (Kafle, 2011), it was necessary for participants to be enrolled in any year beyond the freshman year. Therefore, the qualifying criterion for the study were that each participant must have been a second, third, or fourth year undergraduate student enrolled at the study site; must have been a Chinese citizen; and must not have attended high school in the United States.

Emails containing a link to a preliminary eligibility questionnaire were sent by the International Student and Scholar Services office at the study site to students meeting these criteria. Given the availability of a relatively small population meeting the criteria, a total of six qualified participants were identified and interviewed. Seidman (2013) stated that saturation refers to the point at which the interviewer has spoken with enough participants that they begin to hear the same answers repeated in interviews. Though efforts at snowball sampling were made during the interview process, with participants being asked to refer other qualified students to the eligibility questionnaire, finding that saturation had been reached with the data gathered from the six initial participants, the decision was made to suspend further recruitment efforts.

Four of the six participants interviewed for the study completed their first year of college in the U.S. as sophomores or juniors attending school at the study site. Each of them had transferred from other institutions outside the U.S. (two from China, one from Switzerland, and one from 
Panama). The other two participants completed their first year in the U.S. as freshmen at other institutions in the U.S. One of the students had attended a very small, private school on the west coast of the United States, and the other a large, public school on the east coast of the United States. The participants were enrolled in either Business majors (Marketing and/or Finance) or the Hospitality and Tourism Management major. Four participants were women, all coming to the U.S. from cities or provinces in Northern China, and two participants were men, both of who came to the U.S. from cities in Southern China. Participants ranged in age from 21 to 25 at the time of the study. A table of participant information is available in Appendix A.

\section{Procedures}

Three separate, face-to-face, in-depth interviews were conducted with each of the participants, for a total of 18 interviews. Seidman's (2013) three-interview series model was employed for the study because it, "allows both the interviewer and the participant to explore the participant's experience, place it in context, and reflect on its meaning" (p. 20). In addition, meeting with participants over three separate interviews provided an opportunity for trust to be built between the researcher and the participants, which Seidman suggests is important when there are differences of race or ethnicity between interviewer and participant. Seidman states that, "by returning to the participant three times, an interviewer has the opportunity to demonstrate respect, thoughtfulness, and interest in that individual, all of which can work toward ameliorating skepticism" (p. 102).

Semi-structured interviews were conducted using an interview guide to focus on the key topics to be addressed. Key questions were determined ahead of time, with follow-up questions developing organically based upon participants' responses to the questions. Questions for the semi-structured interviews were developed based upon the conceptual framework and the literature on international students' motivations for seeking a degree in the United States and experiences at institutions in non-English speaking countries. As each of the four coping resources in Schlossberg's Transition Model (1995) encompasses several elements, questions were designed to uncover information about the discreet aspects of that resource. For example, in exploring one element of Schlossberg's Transition Model regarding the individual's role in initiating the transition and the impact it can have on navigating the transition process [related to the resource termed 
"Situation"] (Schlossberg, Waters, \& Goodman, 1995), participants were asked: What made you decide to pursue your undergraduate degree in the United States?, with a follow-up question of: Was this something you had planned to do? "Support" was also identified by Schlossberg et al. (1995) as one of the resources important to individuals in transition. As one of the goals of the research was to understand more about the Institutional Support available to participants during their first year, another question was based on the Culturally Engaging Campus Environments Model's indicators related to Cultural Familiarity and Culturally Relevant Knowledge (Museus, 2014). The question: Would you say you saw your culture reflected in the campus environment through programs, organizations, or other avenues, or that you were able to stay connected to your culture? How/In what ways?, was intended to explore any opportunities the participants had to connect to institutional agents and/or fellow students who share cultural backgrounds, and/or to engage in opportunities that "cultivate, sustain, and increase knowledge of their cultures and communities of origin" (Museus, 2014, p. 210). Potential sources of personal support (not only institutional) were also explored, with the question: What were the greatest sources of support to you during your first-year experience? To ensure that interpretation of the participants' comments was accurate, member checking was done while interviews were being conducted. In member checking, the researcher solicits feedback from the participants as transcriptions and early analysis are completed in order to verify that the researcher's initial interpretation accurately reflects their comments (Merriam, 2009). In this study, it was done during interviews in part because, as a result of language differences, it was often necessary to clarify information to try to encapsulate an idea while an interview session was in progress.

\section{Data Analysis}

Coding. Data analysis was completed using open coding and content analysis. Open coding allows the researcher to consider all the data being reviewed without strict parameters guiding the process, such that categories and themes emerge through an analysis of the material being reviewed (Merriam, 2009). Content analysis in qualitative inquiry also focuses on the emergence of categories or themes from the interview data as it is reviewed (Merriam, 2009). Coding for this study took place in two levels: first-cycle coding, where codes were assigned to give meaning to items of interest in the data; and second-cycle coding, where the first-cycle codes were analyzed further, synthesized, and grouped into categories 
(Saldaña, 2009) or "clusters of meaning" (Creswell, 2007, p. 61) using the conceptual framework as a guide.

A set of predetermined codes taken from the conceptual framework were used at the outset, but the majority of codes emerged through the process of content analysis. Predetermined codes included such broad terms as "Motivation," "Outlook," and "Support," drawn from Schlossberg's Transition Model (1995), and "Cultural Familiarity," and "Campus Environment," drawn from the CECE Model (Museus, 2014). These predetermined codes were used during first-cycle coding, along with both attribute coding, which was used for coding demographic information, and descriptive coding, which was used to summarize the basic idea of a passage or sentence (Saldaña, 2009). The initial, predetermined codes were made intentionally broad to provide a starting point in analysis, but the use of descriptive coding led to more detailed codes with more nuanced meaning. For example, a notation regarding the format of classes in the Chinese educational system and the familiarity of a cohort model was made on several transcripts during first-cycle coding and led to the creation of two new codes. Participants who spoke about how the Chinese class structure had them moving through the same set of classes with the same group of students each day, as opposed to the U.S. structure, which saw them taking different classes with different students, expressed difficulties in creating relationships with their peers because they were not always together. The code "Class Format" was used to capture the participants' acknowledgement of pedagogical difference. Additionally, although the difference in class format had obvious implications for their academic transition to a new pedagogical style, considering it in the context of their larger experience showed that it had an even more significant impact on their social transition. This resulted in the creation of the additional code "Building Relationships." Other codes that emerged independent of those based directly on the conceptual framework included "Jokes," "American Slang/Idioms," "Difficulties with Reading Comprehension," "Difficulties with Spoken Comprehension," "Practical Vocabulary," and "Needed Translation." Each of these codes was connected to the participants' command of English, so a primary code of "Language Proficiency" was identified and each of the related codes were then categorized as sub-codes of "Language Proficiency." At the end of first-cycle coding using this process, a total of 34 primary codes and 230 sub-codes had been identified.

Pattern coding, a process that pulls together several data items into thematically linked categories, and focused coding, which looks at the most 
frequently applied codes to distill the most meaningful themes from the data, were used for second-cycle coding (Miles \& Huberman, 1994; Saldaña, 2009). The sub-codes of "Language Proficiency" described above (along with others not listed), for example, appeared to fall into two main categories, with some falling into both categories. The code of "Jokes," was used about experiences in social settings, and the code of "Difficulty with Reading Comprehension" was used in relation to academic experiences. The codes of "American Slang/Idioms" and "Needed Translation" tied to both social and academic experiences shared by participants. Second-cycle coding resulted in the reduction of initial codes to a total of 24 primary codes and 45 sub-codes, with an additional attribute of "positive" or "negative" assigned, as appropriate, to several of the codes and/or subcodes. In some cases, both negative and positive attributes were assigned. For instance, participants viewed being fully funded by their parents as favorable in most cases, but there were instances where the accompanying sense of obligation hindered students and had a negative impact. As such, the code "Parental Support" was assigned both positive and negative attributes. A sampling of the codes resulting from first and second-cycle coding is provided in Table 2 .

Themes. The general themes that emerged from this process were: motivation, preparation, support, and strategies. Each was connected to the factors identified as part of the "4 S's" (Situation, Self, Support, and Strategies) from the Schlossberg Transition Model (1995). After coding was completed and themes identified, a spreadsheet consisting of transcript excerpts was sorted using the codes and themes, along with sub-codes of social and/or academic domain and the filters of positive and/or negative attributes, in order to create a comprehensive picture of the experiences of these six participants as they moved into and through their first year of college in the United States.

\section{Limitations}

One potential limitation of this study was that participants did not all begin their first year of study in the U.S. as a first-year/freshman student. For the students who attended institutions outside of China prior to their U.S. enrollment, this would potentially have involved language and culture transitions similar to what they experienced in coming to the United States (even if the language at the institution was not English). Though several of the participants in this study had such an experience prior to coming to the 
United States, none of them mentioned their previous experience as they recalled their first year U.S. experiences. Nevertheless, it was important to maintain an awareness that the previous experiences of these students may well have affected the way they managed and understood those which were the focus of this study. Since there was no discreet acknowledgement of any previous experiences by the participants, it is not possible to determine if they had any impact.

\section{Table 2}

Sample of Codes Identified through Data Analysis

\begin{tabular}{|c|c|c|c|}
\hline $\begin{array}{l}\text { First-Cycle } \\
\text { Descriptive } \\
\text { Codes }\end{array}$ & $\begin{array}{l}\text { First-Cycle } \\
\text { Sub-Codes }\end{array}$ & $\begin{array}{l}\text { Second- } \\
\text { Cycle } \\
\text { Pattern } \\
\text { Codes }\end{array}$ & $\begin{array}{l}\text { Second-Cycle } \\
\text { Sub-Codes }\end{array}$ \\
\hline $\begin{array}{l}\text { Expectations for } \\
\text { College in the } \\
\text { U.S. }\end{array}$ & $\begin{array}{l}\text { - Academic } \\
\text { - Social Experience } \\
\text { - Language } \\
\text { - Housing } \\
\text { - Make Friends } \\
\text { - Get Practical } \\
\text { Experience }\end{array}$ & Expectations & $\begin{array}{l}\text { Ex: Academic (+ or -) } \\
\text { Ex: Social/ } \\
\text { Personal (+ or -) } \\
\text { Ex: Negative }\end{array}$ \\
\hline $\begin{array}{l}\text { Language } \\
\text { Proficiency }\end{array}$ & $\begin{array}{l}\text { - Understanding Prof. } \\
\text { - Needed Translation } \\
\text { - American Slang/Idioms } \\
\text { - Practical Vocabulary } \\
\text { - Jokes }\end{array}$ & $\begin{array}{l}\text { Language } \\
\text { Proficiency }\end{array}$ & $\begin{array}{l}\text { LP: Academic }(+ \text { or }-) \\
\text { LP: Social }(+ \text { or }-)\end{array}$ \\
\hline Living Situation & $\begin{array}{l}\text { - Supported by Parents } \\
\text { - Public Transportation } \\
\text { - Needed Car }\end{array}$ & \multirow[t]{2}{*}{$\begin{array}{l}\text { Living } \\
\text { Situation }\end{array}$} & \multirow{2}{*}{$\begin{array}{l}\text { LS: Housing Problems } \\
\text { LS: Housing } \\
\text { Arrangements } \\
\text { LS: } \\
\text { Driving/Transportation } \\
\text { LS: Financial Situation }\end{array}$} \\
\hline Housing & $\begin{array}{l}\text { - Roommate Problems } \\
\text { - Required to Live On- } \\
\text { campus } \\
\text { - Forced to Live Off- } \\
\text { campus } \\
\text { - Found Roommate via } \\
\text { Internet from China }\end{array}$ & & \\
\hline
\end{tabular}

Another potential limitation of the study was the researcher's race/ethnicity as a White, American/Western woman. Since Chinese students place a high value on trust within their close, inner circle of family and friends (Bond, 1991), entering into a dialogue about their backgrounds and experiences with an unknown person from outside of their community could have resulted in challenges to the establishment of a trusting rapport 
in which participants were willing to share their experiences. The Chinese concern with maintaining "face" makes it important to avoid opening oneself to a possible betrayal by those outside of their inner circle, as the results of damaging one's reputation can be far reaching (Bond, 1991). In order to mitigate this issue, recruitment efforts were coordinated through the Office of International Student and Scholar services at the study site. Since the staff members in that office had already established trusting relationships with the students being invited to participate, their willingness to vouch for the researcher may have made it more comfortable for students to take part. Although the participants did share a great deal about their personal experiences, the information they shared was largely limited to the questions on the interview guide, and it was sometimes difficult for them to engage in more organic conversation. Ultimately, it does not appear that this had a negative impact on the study, but having had a research partner with greater knowledge of Chinese culture and language may have garnered even richer data.

Finally, this qualitative study centered on a very narrow sample from the population of international students. Though done intentionally in an effort to disaggregate a specific population from the heterogeneous international student community, it is does not allow for a generalization to other sub-populations. That said, limiting the study to Chinese undergraduates allowed for an evaluation of the experiences of a unique population that represents the fastest growing segment of international students on U.S. campuses. As a result, the findings of this research have value to practitioners working with this population.

\section{RESULTS}

\section{Motivations and Expectations (Situation)}

A variety of motivating factors and expectations shaped the experiences of the study participants' journeys to the United States in pursuit of their college degrees. Among the motivations, each of which aligned with push-pull factors identified in a review of the literature about international student motivation for studying in the U.S., were the external factors of parental influence and the desire for greater job opportunity as a result of obtaining a U.S. degree. In addition, personal motivations were responsible for the decisions of several of these students to come to America. Those personal factors included the desire to "see the outside 
world" and to experience the excitement of being in a place so different from China.

Expectations for what the American college experience would be like were also revealed as a result of the motivations shared by study participants. These ranged from positive hopes for both the academic and social experience -- such as having opportunities to gain practical experience through internships or taking part in a lively residence hall environment that would facilitate friendships with American students -- to negative ones related to language ability and difficulty meeting or making friends. For example, one participant shared her positive hopes for internship experiences by stating, "I want to learn not just focus on the book, the knowledge. I want to go outside I mean, in America hotels. I want to learn more experience" (Skye). On the other hand, a negative expectation related to language was expressed by a participant who stated, "I thought I wouldn't be able to catch up because when I studied... when I would do my TOEFL test, I would barely understand a word what the thing was saying; I barely catch a word" (Chino). As was the case with their motivations, the expectations of the students in this study also aligned with the expectations of international students as identified in the literature. According to Marriott, du Plessis, and $\mathrm{Pu}$ (2010), international students cited expectations that their experience in the U.S. would provide them with a better education than they could have received in their home country, which would lead to greater job opportunities and long-term prosperity. Another expectation cited by Mariott et al. (2010) and reflected in the expectations of study participants was the formation of meaningful friendships with domestic students. Other expectations shared by participants in this study were more specific to their perceived language proficiency and how it would influence their experience, as well as how they anticipated having opportunities to improve their language skills. This was most clearly reflected by a participant who stated, "Before I come here, I expected that I will improve my English very fast, because I will live in a dormitory with international friends and we will speak English every day" (Lucy).

The motivations and expectations shared by study participants exposed three separate, often intersecting, transitions that each student would experience throughout the first year of college in the U.S. - linguistic, academic, and social/personal. Although two of the students entered their institutions as first-time-in-college (FTIC) freshman, neither their expectations nor their transition experiences seem to have differed significantly from those of the participants who had attended college 
previously, regardless of where those students had studied. Furthermore, analysis of the data revealed that although several factors contributed to their success during the first year, a significant number of factors hindered these students' experiences as well.

\section{Obstacles to Success}

Housing. One of the primary obstacles reported by participants, which had a significantly negative impact on both the linguistic and social/personal transitions for these participants, was related to their housing arrangements. Students who did not have access to on-campus housing also received no guidance from their institution about where to look for housing or how to connect with students who were already enrolled at the institution to identify potential roommates. These students were forced to rely on the social media resources to which they had access in China to connect with other Chinese students already at their institution. One participant noted, "It's always Chinese people help Chinese people." As such, these students relied upon themselves and their extended community abroad to identify roommates with whom they moved in without having met, and apartments into which they moved without ever having seen them. Since public transportation was unreliable in their area, this situation also resulted in the added expense of students needing to purchase cars to get around not only to conduct daily activities, but simply to get to their classes.

For the students who received on-campus accommodations, the experiences in their residence halls were no better. Differences in language and culture with their American roommates led to serious issues for both Kat and Chino. Chino shared that in his situation, "I never told them [his roommates or the RA] that I was not good with the stuff they were doing," but his strategy was to avoid being in his room as much as possible. Kat did try to talk to her roommate about problems, but found it difficult because, "It's like we have different habit and culture background. I try to...sometimes when I tried to talk to her, but I don't know what I should say." A third, participant, Tianyao, had difficulty connecting with the American students in his residence hall because he found their drinking and partying distasteful. He stated, "People there [residents of the residence hall], they're just crazy, and sometimes, the thing they did, it's unbelievable. Yes, and especially on Friday night, I saw a lot of drunk guy on the hallway, which is annoying." Unreliable public transportation on and around campus, and the inability to purchase a car, created additional problems for two of these participants. For instance, Chino shared that when he needed 
groceries, he had to calculate the weight of items and plan multiple trips so that he would be able to carry everything he needed in the twenty-minute walk (in tropical summer heat) back to his room.

With respect to each of these participants, the institutions seem to have made many assumptions on behalf of the Chinese students who were entering their campus communities. These assumptions included: the resources available to them to find appropriate accommodations off-campus (if needed); the level of cultural and linguistic knowledge/comfort they might have before being partnered with American roommates who were clearly unprepared or uninterested in supporting them through their firstyear transitions; and the financial resources available to them to cover unanticipated expenses like purchasing a car to get to class or buy groceries. Furthermore, these institutions failed each of the participants by not providing the conditions to have meaningful cross-cultural engagement opportunities in their living spaces or to aid them in the linguistic transition that was so critical to their overall success. Furthermore, they failed the students who lived on-campus by not ensuring they had the means to access necessities without significant hardship.

Lack of support for linguistic transition. Another notable finding was the general failure of institutions to provide conditions that would have supported the linguistic transitions of these participants. All of their transition types - linguistic, academic, and social/personal - were hindered by this lack of support. These transitions must be evaluated independently to more fully understand them, but their intersections must also be considered to fully appreciate their impact on the participants' overall experiences. For instance, each participant noted transition issues that were specifically academic in nature, but the linguistic transition was often involved in terms of understanding professors in a lecture, taking certain types of exams that challenged reading comprehension, or the ability to complete written assignments. Kat indicated that multiple choice tests were much easier for her because even if she did not understand every word of a question, if she could identify key words as they related to the multiple-choice answers, she had a better chance of making a correct choice. Similarly, the social/personal transitions these participants experienced were often challenged not only by cultural differences between themselves and their domestic peers, but by their level of language proficiency and the frustration they experienced in trying to be understood. 
While some students did have the opportunity to live with American roommates, cultural differences and a lack of common ground, coupled with anxiety about their speech, made it difficult for these participants to attempt conversations, resulting in lost opportunities. For Kat, her assignment to a residence hall with an American roommate should have been helpful to her in improving her English, but her lack of confidence with her language level left her unsure about what to say, so she stopped trying to start conversations with her. She also shared that her American roommate would frequently take things that belonged to her, such as bottled water she had purchased for herself and that she kept on her side of the room, but she did not have the confidence to approach her about this. For those who were not afforded the opportunity to live on-campus, minimal contact with domestic students outside of class, and the American class structure that does not use a cohort model, limited their access to support in the linguistic transition as well as the social/personal transition. One participant stated, "...in China we take class like "class 1 , class 2 ," like that. We are a group together to take the same class, but for here every class will have different classmates, so it's very hard to make relationships and make friends" (Lucy).

Inconsistent orientation programs. Another notable finding was the inconsistency of orientation programs for these students. Most participants were unable to recall who hosted their orientation (an International Student Services office, or a New Student Services/Orientation office), or if the orientation they attended was mandatory. Because of the inconsistent information students received from their institutions, they relied on their network of newly made Chinese friends who had already been at the institution for some period of time. This often resulted in them receiving incomplete or inaccurate information which ultimately disadvantaged them. Orientation programs are an institution's first opportunity to exercise the Proactive Philosophies described in the Culturally Engaging Campus Environments Model (Museus, 2014). The failure of these institutions to make clear to students what purpose the orientation program served, what kind of information would be provided, and whether the session was mandatory, represented a lost opportunity to provide these students with tools and resources to set them up for success in their multiple transitions through the first year.

Finally, regardless of the size or type of institution these participants attended and, with a few exceptions, regardless of their age, gender, or area of origin, the experiences of these students - both positive and negative - 
were quite similar. Each of the participants experienced challenges related to language, and most were surprised by this because they felt prepared when they left their homes to come to the U.S. Tianyao, for example, stated, "I expect like everything here is going to be perfect for me, because since I have a higher TOEFL score." Each participant had issues related to housing, even when it was provided by the institution. Each of them relied on their families and friends at home for support and developed networks of Chinese friends at their institutions to provide additional support and information. And, although they attended schools representing three different geographic regions, and ranging in size from 700 students to over 30,000 students, each participant reported that they perceived their campuses as friendly and welcoming. For example, Kat, who attended a very small, private school recalled that, "People are welcoming. Not on purpose, but when you see someone, they are going to, like, smile to you. They gonna say good morning to you. Even like, they don't know who you are." Skye, who attended a large, public institution, also recalled that, "...for the international students, they [faculty members] are very kind and friendly to hang out with us." In considering the challenges and supports to their transitions throughout the first year of college in the United States, since their experiences were so similar, there appears to be an opportunity for meaningful improvement to be made at U.S. institutions, regardless of size or type, and for programs and services to be provided that will be useful to these students across age, gender, and area of origin.

\section{DISCUSSION AND CONCLUSIONS}

Internal and external motivations coinciding with Schlossberg's Transition Model (Schlossberg et al., 1995) were identified for pursuing degrees in the U.S. These not only supported the literature regarding international students' choice to study in the U.S., but expanded upon it. Several push-pull factors identified in previous studies were mentioned among the motivations of students and/or their parents in the present study, including: parental influence on children; the good reputation of particular U.S. programs or institutions; and the desire for greater job opportunity as a result of earning a high-quality degree in the U.S. (Altbach, 2004; Bodycott, 2009; Goodman \& Gutierrez, 2011; Lee, 2008; Mazzarol \& Souter; 2002; Pang \& Appleton, 2004). In addition, and not previously cited in the literature, more than half of the participants in this study cited a desire to go to college in the U.S. to see new and different parts of the world or to return after having visited the 
U.S. for vacation or some other short-term program. As more international students have opportunities to visit America through short-term study and work programs or on vacations with their families, similar personal motivations to pursue degrees in the U.S. may continue to increase.

The Chinese students who took part in this study were prepared in a variety of ways for the transitions they experienced during their first year of college in the United States. The kinds of preparation upon which they relied for coping resources were largely in line with Schlossberg's Transition Model (Schlossberg et al., 1995), and the characteristics of "Self" identified in that model. These included such personal resources as socioeconomic status, positive outlook, and self-reliance. Areas where preparation was most lacking had to do with the students' level of language proficiency and/or the Chinese cultural values with which they were raised. Among the values identified by some study participants were difficulty engaging with strangers and a high level of conservatism or closedmindedness that made it challenging for them to communicate with domestic students who had different backgrounds and values.

Schlossberg's Transition Model (Schlossberg et al., 1995) established "Support" as a coping resource available for individuals in transition and identified the institutions or communities to which the individual belongs among their potential sources of support. Participants identified many ways in which their institutions either provided or failed to provide support to assist them through their academic, social/personal, and linguistic transitions during the first year of college in the U.S., and these aligned with many of the indicators of the Culturally Engaging Campus Environments Model (Museus, 2014). Participants indicated that the opportunity to engage in programs or activities that supported Culturally Relevant Knowledge, and the presence of other Chinese students on campus (Cultural Familiarity) were supportive of their transitions. Similarly, some participants shared stories that indicated the presence of Humanizing Educational Environments and Holistic Support by various institutional agents who took time to develop meaningful relationships with them or who were viewed as trusted sources of information and assistance.

Participants' stories suggested, however, that Proactive Philosophies and Opportunities for Meaningful Cross-Cultural Engagement were very inconsistent and, though some programs or services existed, there were many missed opportunities for these indicators to be addressed at their institutions. Furthermore, some participants reported faculty members who took a personal interest in them, showing evidence of the indicator of 
Culturally Validating Environments, while others did not feel that they could participate fully in the classroom environment because their faculty members made no effort to connect with them or recognize their presence.

Finally, while several participants did some type of community service or volunteering during their first year, none of them identified an opportunity for Cultural Community Service, which the CECE Model suggests gives students an opportunity to give back to their own communities. Clearly, although the CECE Model was designed with diverse domestic minority students in mind, this study demonstrated that many of the indicators identified to support diverse students apply to international student populations as well. Based on the findings of this study, despite the fact that it was developed with domestic minority students in mind, the expansion of the CECE Model to intentionally and explicitly incorporate international students seems warranted.

The primary "Strategies" used by these participants to cope with their transitions during the first year are consistent with those described in Schlossberg's Transition Model, in that they were employed in an effort to exercise some control over their situation or soothe themselves in the midst of a situation that could not be changed (Schlossberg et al., 1995). Some participants opted for social isolation as a strategy for coping with difficult linguistic and social/personal transitions, but this strategy also served as a challenge to those same transitions. By contrast, turning to family members and friends was a highly effective positive strategy for adjusting to a new environment. Each of the participants cited the important role that family members and peers played as sources of information and support, particularly in their social/personal transitions. Attempting to adapt to the new environment was also viewed as a positive strategy employed by some of the participants who did so as a means of exerting control over their situation. That these students felt they had to adapt in order to have a sense of control, as opposed to entering an environment that was created to be supportive of their transition, however, demonstrates the need for greater institutional awareness of the needs of diverse student populations.

\section{IMPLICATIONS}

Based upon the coping resources of self, support, and strategy demonstrated by participants in this study, several suggestions to improve programs and services that facilitate and support the transitions of future Chinese students coming to the United States were identified. 


\section{Orientation}

Since International Student Service (ISS) offices must provide incoming students with critical immigration related information, and New Student Program or Orientation offices typically provide information about advising and registration along with other functional components (e.g., obtaining a student ID, attending presentations about campus resources), it is suggested that these offices work together in the implementation of a unified, mandatory orientation program for all new international students. The content of the program should be tailored to include information and resources about academic and social/personal transitions (e.g., pedagogical styles and structures in the U.S.; the importance of academic advising; how courses are selected and registered for; and social cues and norms for interaction among faculty, staff, and peers), and the role of the linguistic transition in both of those domains. The orientation should be delivered through a multi-tiered approach beginning with an online component available prior to arrival, followed by an in-person program upon arrival, and rounded out via printed materials provided at the in-person program. These formats serve multiple purposes in that the online and printed materials make information available to students on an ongoing basis. Printed materials should be provided in English with a side-by-side translation (e.g., Mandarin) to ensure clarity of the information being provided, and to support linguistic transitions by helping students build their practical vocabulary.

\section{Workshops}

Beyond the orientation program, institutions providing Holistic Support and adhering to Proactive Philosophies, as suggested by the Culturally Engaging Campus Environments Model (Museus, 2014), should make ongoing support and resources available to students. Multiple delivery formats would be appropriate for these resources as well, and might include: in-person workshops, informal gatherings, and additional online materials. As with the content of the orientation program, workshops should cover topics that support the academic, social/personal, and linguistic transitions being experienced by Chinese and other international students. For instance, workshops could provide role playing opportunities for Chinese students to interact with faculty members or their domestic peers; informal gatherings could partner students to practice their English skills in a social setting such as a campus coffee shop; and online materials could focus on preparation for taking the driver's license exam. Student Affairs departments could partner 
with their campus' ISS office and each other to provide these and other culturally relevant programs. Making such information and opportunities available on an ongoing basis would make it easier for students to get information and support for practical matters without having to ask for it.

\section{Housing}

In cases where on-campus housing is made available to Chinese students (or other non-native English speaking international students), Housing/Residence Life staff must make efforts to identify accommodations that are appropriate to support the social/personal transition of these students. Establishing "international residence halls," or even "international floors" within residence halls, that are open to domestic students interested in being paired with international students would provide meaningful opportunities for cross-cultural engagement among willing participants. This sort of intentional effort would demonstrate the institution's support of the social/personal and linguistic transitions of Chinese or other non-native English speakers by placing them in environments, and among individuals, where they can feel welcomed and valued.

\section{Summing Up}

Each of these interventions could be easily implemented or supported by student Affairs departments with limited impact on existing budgets. The process of being intentional about addressing the unique needs of this student population is at the heart of each recommendation. Making these students feel welcomed and valued as members of their campus communities is achievable and should be seen as the responsibility of every area of campus. Student Affairs staff have an opportunity to model the way for being inclusive of Chinese and other international students in their programming and services and not leaving these tasks to the International Student Services office on their campuses.

\section{REFERENCES}

Altbach, P. G. (2004). Higher education crosses borders. Change, 36, 18 - 24. doi: $1080 / 00091380409604964$

Anderson, G., Carmichael, K. Y., Harper, T. J., \& Huang, T. (2009). International students at four-year institutions: Developmental needs, issues and strategies. In S. R. Harper \& S. J. Quaye (Eds.), Student engagement in 
higher education: Theoretical perspectives and practical approaches for diverse populations (pp. 17 -37). New York: Routledge.

Andrade, M. S. (2006). International students in English-speaking universities: Adjustment factors. Journal of Research in International Education, 5(2), 131-154. doi: 10.1177/1475240906065589

Bodycott, P. (2009). Choosing a higher education study abroad destination: What mainland Chinese parents and students rate as important. Journal of Research in International Education, 8, 349-373. doi: 10.117/1475240909345818

Bond, M. H. (1991). Beyond the Chinese face: Insights from psychology. New York: Oxford University Press.

Chan, S. (1999). The Chinese learner: A question of style. Education + Training, 41(6/7), 294-304.

Choudaha, R., Chang, L., \& Kono, Y. (2013, March). International student mobility trends 2013: Towards responsive recruitment strategies. World Education Services, New York. Retrieved from www.wes.org/RAS

Creswell, J. W. (2007). Qualitative inquiry and research design: Choosing among five approaches $\left(2^{\text {nd }}\right.$ ed.). Thousand Oaks, CA: Sage Publications.

Douglass, J. A., \& Edelstein, R. (2009, October). The global competition for talent: The rapidly changing market for international students and the need for a strategic approach in the US. Center for Studies in Higher Education, 8, 122.

Glass, C. R., Buus, S., \& Braskamp, L. A. (2013). Uneven experiences: What's missing and what matters for today's international students. Retrieved from https://gpi.central.edu/supportDocs/Report-on-InternationalStudents.pdf

Goodman, A. E. (2009). The case for international education. Retrieved from http://www.america.gov/st/educenglish/2009/August/20090807101553cMretroPO.6041987.html

Goodman, A. E., \& Gutierrez, R. (2011). The international dimension of U.S. higher education: Trends and new perspectives. In R. Bhandari \& P. Blumenthal (Eds.), International students and global mobility in higher education (pp. 83-106). New York: Palgrave Macmillan.

Hanassab, S. (2006). Diversity, international students, and perceived discrimination: Implications for educators and counselors. Journal of Studies in International Education, 10, 157-172.

Hofstede, G. \& Bond, M. (1988). The Confucius connection: From cultural roots to economic growth. Organizational Dynamics, 16(4), 5-21.

ICEF Monitor. (2014). Summing up international student mobility in 2014. http://monitor.icef.com/2014/02/summing-up-international-studentmobility-in-2014/ 
Institute of International Education. (2013). Top 25 places of origin of international students, 2011/12-2012/13. Open Doors Report on International Educational Exchange. Retrieved from http://www.iie.org/opendoors

Institute of International Education. (2015a). International students enrollment trends, 1948-2015. Open Doors Report on International Educational Exchange. Retrieved from http://www.iie.org/Research-andPublications/Open-Doors/Data/International-Students/EnrollmentTrends/1948-2016

Institute for International Education. (2015b). Open doors fact sheet: China. Open Doors Report on International Educational Exchange. Retrieved from http://www.iie.org/Research-and-Publications/Open-Doors/Data/FactSheets-by-Country/2015\#.V8bY7vkrKUk

Kafle, N. P. (2011). Hermeneutic phenomenological research method simplified. Bodhi: An Interdisciplinary Journal, 5, 181 - 200.

Kim, S., \& Kim, R. H. (2010). Microaggressions experienced by international students attending U.S. institutions of higher education. In D. W. Sue (Ed.), Microaggressions and Marginality: Manifestations, Dynamics, and Impact (pp. 171-191). Hoboken, N.J.: Wiley.

Laverty, S. (2003). Hermeneutic phenomenology and phenomenology: A comparison of historical and methodological considerations. International Journal of Qualitative Methods, 2(3), 21 - 35.

Lee, J. J. (2008). Beyond borders: International student pathways to the United States. Journal of Studies in International Education, 12, 308 - 327. doi: $10.1177 / 1028315307299418$

Lee, J. J. (2010). International students' experiences and attitudes at a US host institution: Self-reports and future recommendations. Journal of Research in International Education, 9, $66-84$.

Lee, J. J., \& Rice, C. (2007). Welcome to America? International student perceptions of discrimination. Higher Education, 53, 381 - 409. doi: 10.1007/s10734-005-4508-3

Marriott, J., du Plessis, A. J., \& Pu, M. (2010). Export education: How do international students experience New Zealand's service to them? Interdisciplinary Journal of Contemporary Research in Business, 2(8), 2941.

Mazzarol, T., \& Soutar, G. N. (2002). "Push-pull" factors influencing international student destination choice. The International Journal of Educational Management, 16(2/3), 82-90.

McMurtrie, B., \& Fischer, K. (2008, June 6). Red tape is a top concern for international educators. The Chronicle of Higher Education, p. A25.

Merriam, S. B. (2009). Qualitative research: A guide to design and implementation. San Francisco: Jossey-Bass.

Miles, M. B., \& Huberman, A. M. (1994). Qualitative data analysis ( $2^{\text {nd }}$ ed.). Thousand Oaks, CA: Sage Publications. 
Museus, S. D. (2014). The culturally engaging campus environments (CECE) model: A new theory of success among racially diverse college student populations. In M. B. Paulsen (Ed.), Higher education: Handbook of theory and research (pp. 189 - 227). doi:10.1007/978-94-017-8005-6_5

Pang, B., \& Appleton, N. (2004). Higher education as an immigration path for Chinese students and scholars. The Qualitative Report, 9(3), 500-527.

Reid, L. D., \& Radhakrishnan, P. (2003). Race matters: The relation between race and general campus climate. Cultural Diversity and Ethnic Minority Psychology, 9(3), 263-275.

Russell, J., Rosenthal, D., \& Thomson, G. (2010). The international student experience: Three styles of adaptation. Higher Education, 60, 235 - 249.

Saldaña, J. (2009). The coding manual for qualitative researchers. London: Sage Publications.

Schlossberg, N. K., Waters, E. B., \& Goodman, J. (1995). Counseling adults in transition: Linking practice with theory $\left(2^{\text {nd }}\right.$ ed.). New York, NY: Springer Publishing Company.

Seidman, I. (2013). Interviewing as qualitative research: A guide for researchers in education and the social sciences $\left(4^{\text {th }}\right.$ ed.). New York: Teachers College Press.

Smith, R. A., \& Khawaja, N. G. (2011). A review of the acculturation experiences of international education. International Journal of Intercultural Relations, 35, 699-713. doi: 10.1016/j.intrel.2011.08.004

Tan, T., \& Weidman, J. C. (2013). Chinese graduate students' adjustment to academic demands in American universities. In T. Coverdale-Jones (Ed.), Transnational higher education in the Asian context (pp. 118-131). New York: Palgrave Macmillan.

Watson, L. W., Terrell, M. C., Wright, D. J., Bonner II, F. A., Cuyjet, M. J., Gold, J. A., . . Person, D. R (2002). How minority students experience college: Implications for planning and policy. Sterling, VA: Stylus Publishing.

Yu, A. (1996). Ultimate life concerns, self, and Chinese achievement motivation. In M. H. Bond (Ed.), The handbook of Chinese psychology (pp. 225-246), New York: Oxford University Press. 


\section{APPENDIX A}

\section{Table 1: Participant Information}

\begin{tabular}{|c|c|c|c|c|c|}
\hline $\begin{array}{c}\text { Student } \\
\text { Pseudonym( } \\
\text { Gender) } \\
\text { Age } \\
\end{array}$ & $\begin{array}{l}\text { City of } \\
\text { Origin }\end{array}$ & $\begin{array}{l}\text { Transitioned } \\
\text { from Other } \\
\text { Institution }\end{array}$ & $\begin{array}{c}\text { U.S. } \\
\text { Institution } \\
\text { Type }\end{array}$ & $\begin{array}{l}\text { Year in } \\
\text { College at } \\
\text { Transition }\end{array}$ & Major \\
\hline $\begin{array}{c}\text { Ada } \\
\left(\begin{array}{c}\text { Female }) \\
25\end{array}\right.\end{array}$ & $\begin{array}{l}\text { Shenyang } \\
\text { (North) }\end{array}$ & $\begin{array}{c}\text { Yes; } \\
\text { Switzerland }\end{array}$ & $\begin{array}{c}\text { Large Public } \\
\text { (Southeastern } \\
\text { U.S.) }\end{array}$ & $3^{\text {rd }}$ Year & $\begin{array}{l}\text { Hospitality/ } \\
\text { Tourism } \\
\text { Management }\end{array}$ \\
\hline $\begin{array}{c}\text { Chino } \\
\text { (Male) } \\
24\end{array}$ & $\begin{array}{l}\text { Guangzhou } \\
\text { (South) }\end{array}$ & $\begin{array}{c}\text { Yes; } \\
\text { Panama }\end{array}$ & $\begin{array}{c}\text { Large Public } \\
\text { (Southeastern } \\
\text { U.S.) }\end{array}$ & $3^{\text {rd }}$ Year & $\begin{array}{c}\text { International } \\
\text { Business/ } \\
\text { Finance }\end{array}$ \\
\hline $\begin{array}{c}\text { Kat } \\
(\text { Female }) \\
21\end{array}$ & $\begin{array}{l}\text { Inner } \\
\text { Mongolia } \\
\text { (North) }\end{array}$ & No & $\begin{array}{c}\text { Small Private } \\
\text { (West Coast } \\
\text { U.S.) }\end{array}$ & N/A & Marketing \\
\hline $\begin{array}{c}\text { Lucy } \\
\text { (Female) } \\
21\end{array}$ & $\begin{array}{l}\text { Beijing } \\
\text { (North) }\end{array}$ & $\begin{array}{l}\text { Yes; } \\
\text { China }\end{array}$ & $\begin{array}{c}\text { Large Public } \\
\text { (Southeastern } \\
\text { U.S.) }\end{array}$ & $3^{\text {rd }}$ Year & $\begin{array}{l}\text { Hospitality/ } \\
\text { Tourism } \\
\text { Management }\end{array}$ \\
\hline $\begin{array}{c}\text { Skye } \\
\text { (Female) } \\
23\end{array}$ & $\begin{array}{l}\text { Qingdao } \\
\text { (North) }\end{array}$ & $\begin{array}{l}\text { Yes; } \\
\text { China }\end{array}$ & $\begin{array}{c}\text { Large Public } \\
\text { (Southeastern } \\
\text { U.S.) }\end{array}$ & $3^{\text {rd }}$ Year & $\begin{array}{l}\text { Hospitality/ } \\
\text { Tourism } \\
\text { Management }\end{array}$ \\
\hline $\begin{array}{c}\text { Tianyao } \\
\text { (Male) } \\
21\end{array}$ & $\begin{array}{l}\text { Nanjing } \\
\text { (South) }\end{array}$ & No & $\begin{array}{c}\text { Large Public } \\
\text { (North East } \\
\text { U.S.) }\end{array}$ & N/A & Finance \\
\hline
\end{tabular}

KERRIE A. MONTGOMERY, PhD, is Director of Campus Life at Florida International University's Biscayne Bay Campus in Miami, FL. Her major research interests lie in the area of understanding the needs of international students in the U.S. and providing support for their success. Email: kmontgom@fiu.edu 